\title{
Low-latitude scintillation occurrences around the equatorial anomaly crest over Indonesia
}

\author{
P. Abadi ${ }^{1,3}$, S. Saito ${ }^{2}$, and W. Srigutomo ${ }^{3}$ \\ ${ }^{1}$ Space Science Center, Indonesian National Institute of Aeronautics and Space (LAPAN), Bandung, West Java, Indonesia \\ ${ }^{2}$ Electronic Navigation Research Institute (ENRI), Chofu, Tokyo, Japan \\ ${ }^{3}$ Physics Department, Institut Teknologi Bandung (ITB), Bandung, West Java, Indonesia
}

Correspondence to: P. Abadi (prayabadi@bdg.lapan.go.id)

Received: 13 June 2013 - Revised: 12 November 2013 - Accepted: 15 November 2013 - Published: 16 January 2014

\begin{abstract}
We investigated low-latitude ionospheric scintillation in Indonesia using two GPS receivers installed at Bandung $\left(107.6^{\circ} \mathrm{E}, 6.9^{\circ} \mathrm{S}\right.$; magnetic latitude $\left.17.5^{\circ} \mathrm{S}\right)$ and Pontianak $\left(109.3^{\circ} \mathrm{E}, 0.02^{\circ} \mathrm{S}\right.$; magnetic latitude $\left.8.9^{\circ} \mathrm{S}\right)$. This study aimed to characterise climatological and directional ionospheric scintillation occurrences, which are useful not only for the physics of ionospheric irregularities but also for practical use in GNSS (global navigation satellite system)based navigation. We used the deployed instrument's amplitude scintillation (S4 index) data from 2009, 2010, and 2011; the yearly SSN (sunspot-smoothed numbers) were 3.1, 16.5 , and 55.9, respectively. In summary, (1) scintillation occurrences in the post-sunset period (18:00-01:00 LT) during equinox months (plasma bubble season) at the two sites can be ascribed to the plasma bubble; (2) using directional analyses of the two sites, we found that the distribution of scintillation occurrences is generally concentrated between the two sites, indicating the average location of the EIA (equatorial ionisation anomaly) crest; (3) scintillation occurrence enhancements for the two sites in field-aligned directions are herein reported for the first time by ground-based observation in a low-latitude region; (4) distribution of scintillation occurrences at Pontianak are concentrated in the southern sky, especially in the southwest direction, which is very likely associated with the plasma bubble tilted westward with increasing latitude; and (5) scintillation occurrence in the post-midnight period in the non-plasma-bubble season is the most intriguing variable occurring between the two sites (i.e. post-midnight scintillations are observed more at Bandung than Pontianak). Most of the post-midnight scintillations observed at Bandung are concentrated in the northern sky, with low elevation angles. This might be due to the amplitude of
\end{abstract}

irregularities in certain directions, which may be effectively enhanced by background density enhancement by the EIA and because satellite-receiver paths are longer in the EIA crest region and in a field-aligned direction.

Keywords. Ionosphere (ionospheric irregularities)

\section{Introduction}

Ionospheric irregularities associated with the plasma bubble are a normal occurrence over equatorial and low-latitude regions. The plasma bubble is generated in the bottom-side of the $\mathrm{F}$ region at the magnetic equator after sunset through the Rayleigh-Taylor (RT) plasma instability mechanism. Previous studies have investigated the morphological characteristics of the plasma bubble (e.g. Mendillo and Baumgardner, 1982; Ogawa et al., 2005) and found that the plasma bubble extends from the magnetic equator to, or beyond, the crest of the equatorial ionisation anomaly (EIA). The east-west cross sections extend several hundred kilometres, are tilted westward in both hemispheres with increasing latitude, have a bifurcation feature, are drifting eastward, and are also associated with TEC (total electron content) depletion. Previous authors have studied plasma bubble dependence on solar activity, longitude, and geomagnetic activity. Tsunoda (1985) resolved that seasonal and longitudinal occurrences of the plasma bubble are most frequent when the solar terminator is most closely aligned with the geomagnetic meridian. Maruyama and Matuura (1984) reported a significant occurrence of the plasma bubble associated with low to high solar activity in the equatorial region during equinoctial months in the Asian sector (see also Burke et al., 2004). These authors 
also investigated the dependence of the plasma bubble on magnetic activity.

Previous studies have also found that various scale sizes of irregularity exist inside the plasma bubble, causing a scintillation radio signal from VHF up to the $\mathrm{C}$ band. Basu et al. (1978) investigated plasma depletion irregularities associated with the plasma bubble and found several spatial scale sizes. Metre-scale irregularities cause VHF backscatter, and hundred-metre- to kilometre-scale irregularities cause scintillation on the UHF band. Recently, de Paula el al. (2010) observed the coexistence of both kilometre- and hundredmetre scales in the underlying plasma bubble and also observed that the drifting of hundred-metre scales at two conjugate sites were comparable. In the case of the global positioning system (GPS), an irregularity of an approximately $400 \mathrm{~m}$ scale size at an altitude of approximately $300 \mathrm{~km}$ causes scintillation in the $\mathrm{L} 1$ signal $(1.57542 \mathrm{GHz})$. This is because the scale size of the irregularity at a certain altitude corresponds to the first Fresnel zone, $D=\sqrt{2 \lambda z}$, where $D$ is the scale size of the irregularity, $\lambda$ is the radio wavelength, and $z$ is the altitude of the ionosphere (Pi et al., 1997). Basu et al. (1978) also reported more frequent and stronger scintillations associated with the plasma bubble during the solar maximum period and a drastic reduction in both the frequency and intensity of scintillations during the solar minimum period. Recently, Otsuka et al. (2009) found VHF radar backscatter echoes in the post-midnight period and argued that they were related to the different characteristics of the irregularities. Therefore, many questions related to low-latitude ionospheric irregularities remain unsolved.

In addition to the scientific interest for ionospheric physics, research on ionospheric irregularities has become increasingly important because these phenomena can cause fluctuation in the signal strength of trans-ionospheric links, such as GNSS (global navigation satellite system)-based (including GPS) navigation. Ionospheric scintillation associated with ionospheric irregularities remains a major concern regarding space weather effects on trans-ionospheric systems, particularly at equatorial and low-latitude regions. Basu et al. (2002) stated that scintillation forecasting in the equatorial region remains challenging. At these regions, amplitude scintillation, whereby the amplitude of the signals fluctuates because of ionospheric irregularities, is dominant. Seo et al. (2011) stated that a GPS aviation receiver might lose its carrier tracking lock under deep fading due to strong ionospheric scintillation and that a lost channel cannot be used for position calculation until the lock is re-established.

The occurrence of low-latitude ionospheric irregularities shows regional variability. For example, there is a significant longitudinal difference in seasonal variation. The amplitude of irregularities tends to be larger in high-electron-density regions, such as the EIA. Consequently, GPS scintillation will be higher around this region (de Paula et al., 2003). The equatorial electrojet shows a strong longitudinal variation (Doumouya and Cohen, 2004). Because the equatorial electrojet is driven by the dynamo electric field, regional variation in the EIA and therefore in scintillation occurrence is expected. Characterising regional scintillation is also useful for supporting GNSS-based navigation. We sought to build a regional ionospheric scintillation model over the Indonesian sector. Beniguel et al. (2009) analysed scintillation data obtained at Bandung, Indonesia, in 2006 and showed that they occur mostly northward of Bandung. However, as the analysis was conducted on data obtained at a single location, over one year, and in a low solar activity period, the results are not sufficient to account for solar activity dependence.

In this study, we investigate low-latitude ionospheric scintillations using GPS receivers that were installed in two sites in Indonesia. Our study aims to show the characteristics of GPS scintillation associated with low-latitude ionospheric disturbances. The spatial distribution of scintillation occurrences is discussed in relation to the ionospheric structure. Furthermore, to support practical use, we developed a basic directional characteristic of scintillation occurrences to support GNSS-based navigation.

\section{Observation setup}

The data used for this study were collected from two GPS receivers installed at the Bandung $\left(107.6^{\circ} \mathrm{E}, 6.9^{\circ} \mathrm{S}\right.$; magnetic latitude $\left.17.5^{\circ} \mathrm{S}\right)$ and Pontianak $\left(109.3^{\circ} \mathrm{E}, 0.02^{\circ} \mathrm{S}\right.$; magnetic latitude $8.9^{\circ} \mathrm{S}$ ) stations, Indonesia, as shown in Fig. 1. The instruments installed at both stations are Novatel GSV4004B dual-frequency GPS (L1 of $1.57542 \mathrm{GHz}$ and $\mathrm{L} 2$ of $1.22760 \mathrm{GHz}$ ) receivers with choke ring antennas. The receivers can track up to 12 GPS satellites in the sky and measure amplitude and phase scintillations. In general, the Bandung station is under the southern crest of the equatorial anomaly region, whereas the Pontianak station is equatorward of the equatorial anomaly crest. This observation geometry permitted us to study the latitudinal variation of ionospheric irregularities, from the magnetic equator to the crest of the equatorial anomaly region over the Indonesian sector.

The GSV4004B receiver measures amplitude scintillation at a sampling rate of $50 \mathrm{~Hz}$. The amplitude scintillations, as indicated by the $\mathrm{S} 4$ index, are estimated by the receiver at $60 \mathrm{~s}$ intervals. There are two types of S4 indices: total $\mathrm{S} 4\left(\mathrm{~S} 4_{\text {tot }}\right)$, which includes scintillation due to ambient noise and multipath effects, and correction to the total $\mathrm{S} 4$ ( $\left.\mathrm{S} 4_{\text {corr }}\right)$, which represents the effects of ambient noise. The receiver can measure the standard deviation of the carrier phase for five different time intervals every $60 \mathrm{~s}(1,3,10,30$, and $60 \mathrm{~s}$ phase sigma). The receiver also computes code-carrier divergence (CCDiv) at a rate of $1 \mathrm{~Hz}$, which is tracked on $\mathrm{L} 1$. The standard deviation of CCDiv (sigma-CCDiv) per $1 \mathrm{~min}$ interval is computed for each satellite by the receiver. 


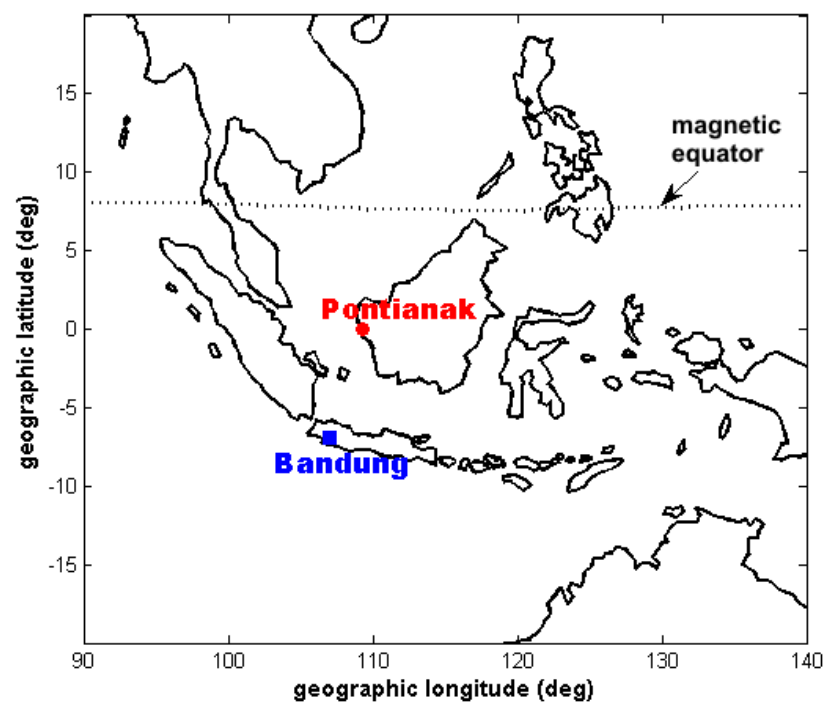

Fig. 1. The observation geography for studying latitudinal variation of ionospheric irregularities over the Indonesian sector.

\section{Ionospheric scintillation analysis}

In this study, we used the amplitude scintillation data obtained from the Bandung and Pontianak stations from January 2009 to December 2011 (3 yr). For this study, data with an elevation angle higher than 10 degrees were used. As described in Sect. 2, parameter $\mathrm{S} 4_{\text {tot }}$ should be corrected because of multipath effects and included ambient noise. We defined the corrected S4 (S4), which indicated ionospheric scintillation, by

$\mathrm{S} 4=\sqrt{\mathrm{S} 4_{\text {tot }}^{2}-\mathrm{S} 4_{\text {corr }}^{2}}$

This formula is the same as that used by Dubey et al. (2006). However, if only this formula is used, S4 may still contain multipath effects, particularly in signals at low elevation angles. As described in Sect. 1, one of the study goals was to establish a basic model of scintillation occurrence characteristics for GNSS-based navigation systems. For the practical use of satellite-based navigation in aviation, in which satellites at elevation angles down to 5 degrees are used, it is important to determine scintillation information at low elevation angles; however, data at elevation angles lower than 30 degrees were discarded in previous ionospheric studies to avoid multipath effects. Thus, it is important to distinguish between the amplitude fluctuations caused by ionospheric effects versus those from multipath effects.

Van Dierendonck and Hua (2001) have shown with the same type of receiver that the sigma-CCDiv is indicative of multipath and noise effects. CCDiv is the difference between code and carrier-phase measurements in the GPS signal. Because CCDiv due to multipath effects is much larger than that due to ionospheric scintillation, this parameter can be used to distinguish between high S4 values due to multipath versus
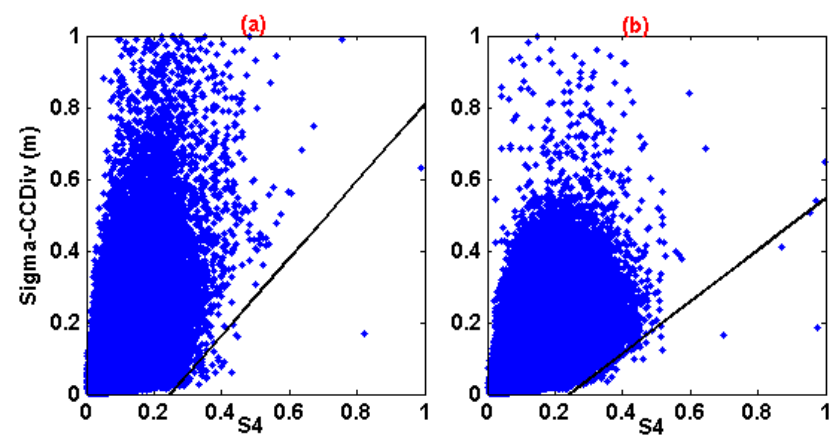

Fig. 2. The signal-to-noise or multipath effects for (a) Bandung and (b) Pontianak data. The data with a sigma-CCDiv value above the line were excluded from the data analysis.

those due to ionospheric scintillation. Van Dierendonck and Hua (2001) established a method (also used for this study) for separating multipath and ionospheric scintillation signals, as follows: sigma-CCDiv is plotted against S4, and the dividing-line separator between a signal with multipath and ionospheric effects is determined. The data with higher sigma-CCDiv values than the dividing-line separator are determined to be affected by the multipath, whereas low sigmaCCDiv values with enhanced S4 are determined to be due to the ionosphere. In this study, we followed this technique to exclude multipath signals in the data analysis.

We examined the S4 and sigma-CCDiv relationship for days without ionospheric scintillation, and 55 and 46 days in 2010 were chosen as non-ionospheric scintillation days for Bandung and Pontianak, respectively. The selection of nonionospheric scintillation days was conducted visually using the following: (1) we first examined a day number versus local time (LT) plot of unfiltered scintillation occurrences for night-time and only during 2010; (2) we then eliminated the days that contain scintillation occurrences with S4 values $>0.2$ over a period of more than $1 \mathrm{~h}$ and that were unrepeated every day with a 4 min shift.

We plotted all of the sigma-CCDiv values against S4 obtained from non-scintillation days for both stations, as shown in Fig. 2. In the figure, the blue dots indicate the distribution of signals with only multipath effects (non-ionospheric effects); the sigma-CCDiv values of signals with only multipath effects are higher, which is consistent with Van Dierendonck and Hua (2001). Based on the plot, we determined the dividing-line separator to distinguish data into true ionospheric scintillation and multipath-affected data. We manually determined the dividing line so that the non-scintillation data are above the line and fit the bottomside envelope of the non-scintillation data. It should be noted that the dividingline separators are not the same for Bandung and Pontianak, because the multipath environment is different for each site.

We also plotted the distribution of the scintillation occurrences with $\mathrm{S} 4$ values $>0.2$ obtained from non-scintillation day data onto an azimuth-elevation coordinate (sky plot), as 

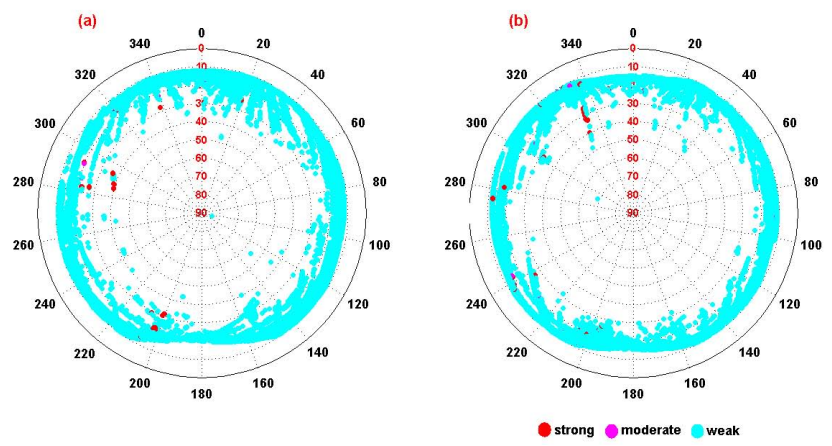

Fig. 3. The elevation-azimuth plot of non-ionospheric scintillation occurrences for (a) Bandung and (b) Pontianak. Strong ( $\mathrm{S} 4>0.8$ ), moderate $(0.5<\mathrm{S} 4<0.8)$, and weak $(0.2<\mathrm{S} 4<0.5)$ scintillation events are indicated by the red, magenta, and cyan colours, respectively. The azimuth angle is measured clockwise from the geographic north.

shown in Fig. 3. We grouped scintillations into three intensity categories, weak $(0.2<\mathrm{S} 4<0.5)$, moderate $(0.5<\mathrm{S} 4<0.8)$, and strong $(S 4>0.8)$, and plotted them onto the sky plot. Figure $3 \mathrm{a}$ shows the distribution of scintillations for Bandung, which we believe are non-ionospheric effects. These scintillations are distributed iso-azimuthally at low elevation angles (less than 30 degrees). This indicates the scintillations are due to ground multipath affects. Figure $3 b$ is the same as Fig. 3a but refers to Pontianak. The figure also shows the distribution of scintillations without ionospheric effects for Pontianak that are also distributed iso-azimuthally at less than 30 degrees in elevation, which indicates that they are due to ground multipath affects. These results also support the conclusion that the higher $\mathrm{S} 4$ values during the non-scintillation days are due to multipath effects.

To illustrate the differences between data analysis with and without the sigma-CCDiv filter, Fig. 4 shows plots of maximum S4 values among all satellites tracked in a 1 min period from Bandung and Pontianak data during March 2010. Figure $4 \mathrm{a}$ and $\mathrm{b}$ show the maximum S4 values without the filter for Bandung and Pontianak, respectively. The plots are very noisy because of the diagonal patterns of scintillation. This indicates that the same S4 variation is repeated everyday with a certain constant time shift and strongly suggests that it is artificial. Each GPS satellite will be detected in the same direction at approximately four minutes earlier every day by the ground-based GPS receiver, and the same multipath condition is also repeated in this way. Thus, the diagonal patterns on the figures are likely caused by multipath effects. We could still recognise strong ionospheric scintillations on the plot indicated by horizontal patches of scintillation. However, it is difficult to distinguish weak scintillations from multipath effects. Figure $4 \mathrm{c}$ and $\mathrm{d}$ show the scintillation analysis after applying the sigma-CCDiv filter for the Bandung and Pontianak data, respectively. The filter removed most of the diagonal patterns associated with multipath effects on the
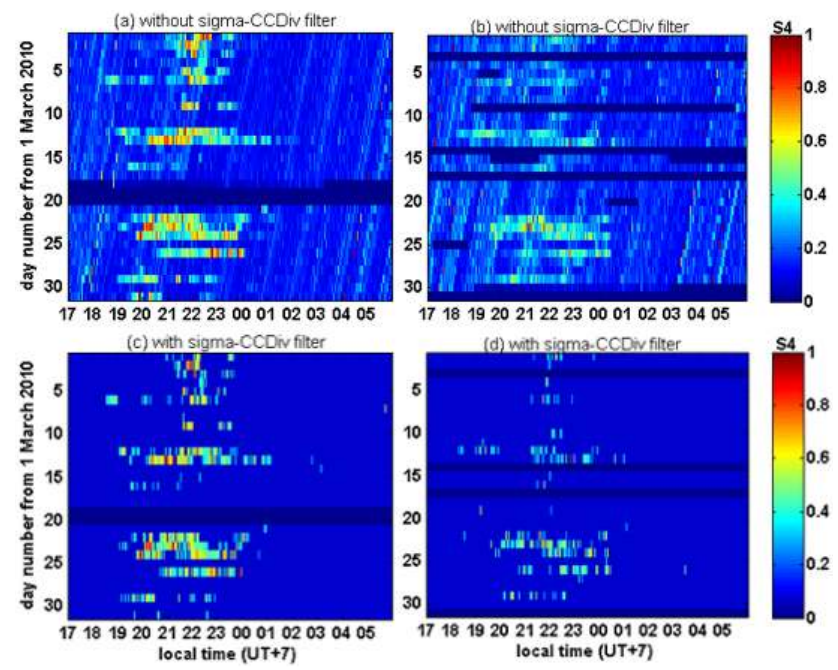

Fig. 4. A comparison between the plot of scintillation occurrences without the sigma-CCDiv filter for (a) Bandung and (b) Pontianak data, and with the filter for (c) Bandung and (d) Pontianak data.

analysis plot. Thus, we can clearly see the patches of scintillation from weak to strong intensities. As the filter allows us to distinguish weaker S4 ionospheric effects from those by multipath effects, we can choose true events of ionospheric scintillation, even when scintillation occurs at low elevation angles.

\section{Results and discussion}

The yearly smoothed sunspot numbers (SSN) were 3.1, 16.5, and 55.7 for 2009, 2010, and 2011, respectively. We analysed climatological night-time ionospheric scintillation occurrences from 17:00 to 06:00 LT. It should be noted that LT is equal to UT (universal time) plus $7 \mathrm{~h}$. We selected the highest S4 for each satellite filtered in a $1 \mathrm{~min}$ period, which is the case in Fig. 4.

\subsection{Climatological analysis}

Using the day-versus-LT plot allowed us to characterise the seasonal and local time variation of ionospheric scintillation occurrences. Figure 5a-c show the seasonal and local time variation of ionospheric scintillation occurrences for Bandung during 2009, 2010, and 2011. As illustrated in the figures, the ionospheric scintillation occurrences have two peaks, between days 50 and 100 and between 200 and 300, i.e. around equinox months. Ionospheric scintillations clearly occur after sunset until around midnight (19:00-01:00 LT). Furthermore, their occurrences were enhanced from 2009 to 2011 with increasing solar activity. The results shown in Fig. $5 \mathrm{~d}-\mathrm{f}$ are the same as in Fig. 5a-c but refer to Pontianak during 2009, 2010, and 2011, revealing that the seasonal variation of ionospheric scintillation occurrences shows a 

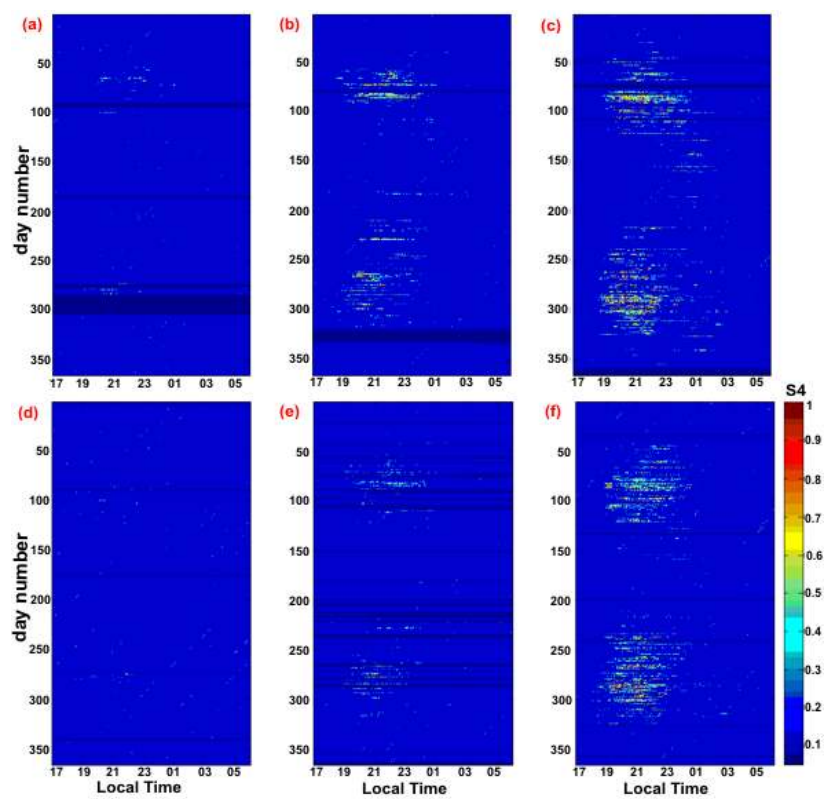

Fig. 5. Seasonal and local time variation of scintillation occurrences at Bandung in (a) 2009, (b) 2010, and (c) 2011 and at Pontianak in (d) 2009, (e) 2010, and (f) 2011. The dark region indicates that no data were observed.

similar pattern to that in Bandung. The scintillations associated with plasma bubbles increase with increasing solar activity, and the peaks of occurrences are in the equinox month for the Indonesian sector (Burke et al., 2004; Tsunoda, 1985), consistent with our results.

We defined post-sunset scintillation as ionospheric scintillations occurring after sunset until approximately midnight. At both Bandung and Pontianak (in our cases), the $400 \mathrm{~m}$ scale irregularities causing GPS scintillations disappear at approximately 01:00 LT, and this result is consistent with previous studies (Basu et al., 1978; Otsuka et al., 2006). Our result related to these post-sunset scintillation occurrences can be ascribed to equatorial plasma bubbles.

\subsection{Directional analysis}

In this section, we analyse the spatial distribution of scintillation occurrences. Bandung and Pontianak are separated by approximately 6 degrees in latitude. As stated before, scintillation intensity depends on the background electron density (Basu et al., 1988); because the electron density in the equatorial anomaly region is high, higher scintillation occurrence would be expected around the region. The electron density distribution has significant latitudinal variation, especially around the EIA region. Plasma bubbles that cause scintillation are generated at the magnetic equator and develop poleward. Thus, the spatial distribution of scintillation occurrence is expected to have latitudinal differences. It is also important for practical applications to elucidate the spatial distribution of scintillation occurrences so that GNSS-based
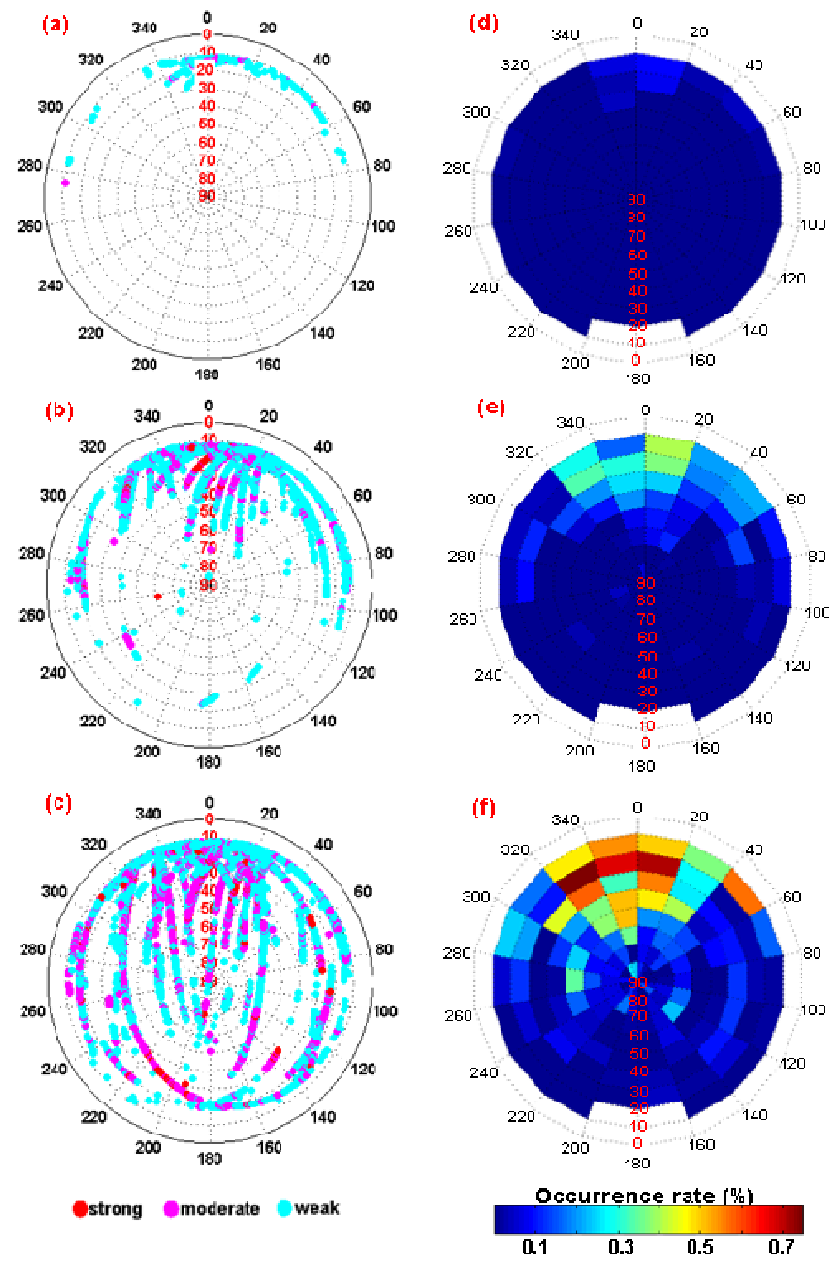

Fig. 6. The directional distribution of ionospheric scintillation for Bandung during (a) 2009, (b) 2010, and (c) 2011 and their occurrence rate during (d) 2009, (e) 2010, and (f) 2011.

system designers can evaluate the impacts of scintillations on the performance of their systems. Therefore, we analysed ionospheric scintillation occurrences as a function of the elevation and azimuth angles for both sites. In addition, we counted the percentage occurrence of ionospheric scintillations at intervals of 10 and 20 degrees in elevation and azimuth angles, respectively.

Figure 6 shows the directional distribution of ionospheric scintillations (sky plots) and their occurrence rate for Bandung. Figure $6 \mathrm{a}-\mathrm{c}$ show the occurrences of ionospheric scintillation over azimuth and elevation angles for Bandung during 2009, 2010, and 2011. As shown in Fig. 5 (and other figures), the number of ionospheric scintillation events and the intensity increased with increasing solar activity. Additionally, ionospheric scintillation distributions develop from the northern to southern sky of Bandung as solar activity increases. Figure $6 \mathrm{~d}-\mathrm{f}$ provide more quantitative directional distribution during 2009, 2010, and 2011. From these figures, it is observed that the distribution is concentrated in the 

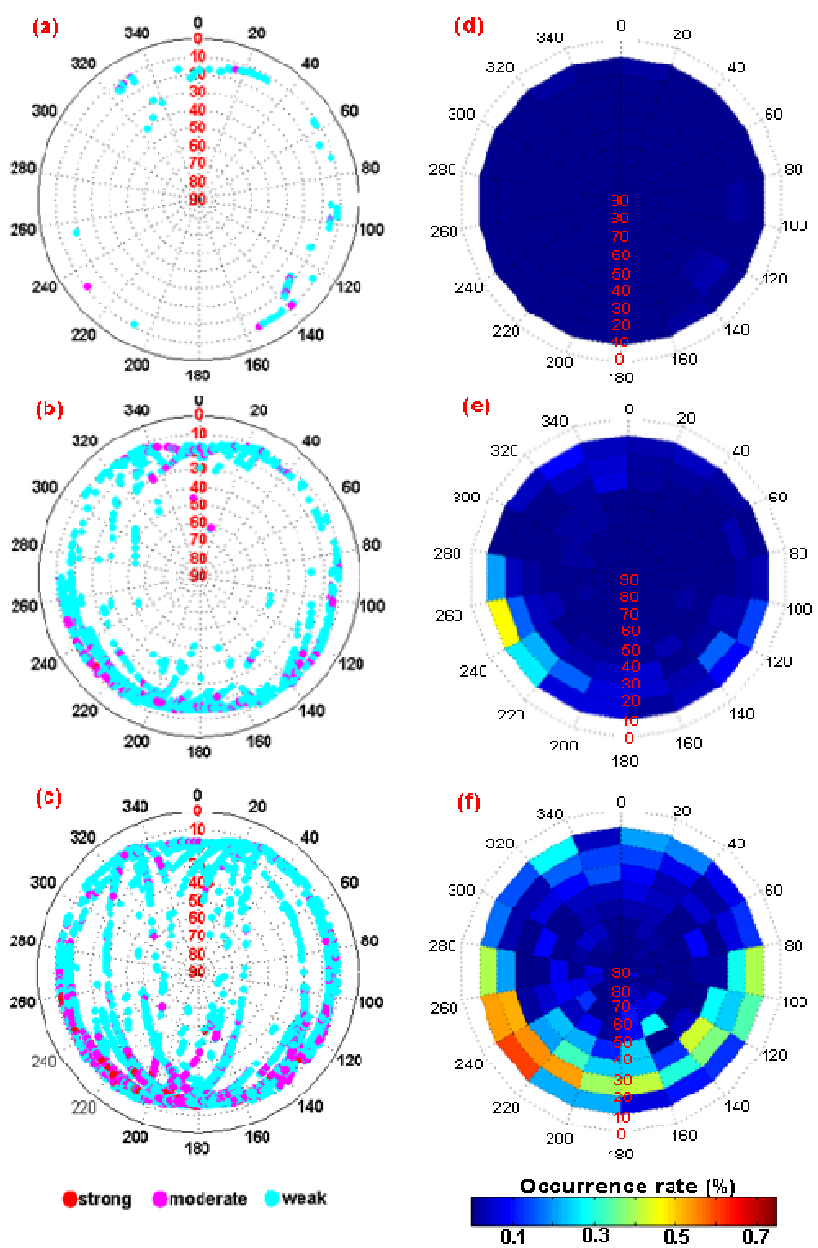

Fig. 7. Same as Fig. 6 but for Pontianak.

northern sky (equatorward) of Bandung. We also found it interesting that, in the directional analysis for Bandung, the highest concentration of occurrences at 20-30 degrees in elevation angle were in the northern sky. This result is also consistent with Beniguel et al. (2009), who observed GPS scintillations with an intensity more than 0.5 , mostly occurring northward of Bandung. Our result also indicates that ionospheric scintillations still occur in the northern sky of Bandung, though the solar activity increased from 2009 to 2011.

Figure 7 shows the results for Pontianak. The number of occurrences was again increased according to the increasing solar activity from 2009 to 2011, as shown in Fig. 7a-c. The distribution of occurrences for Pontianak is quite different from Bandung. Figure 7 shows that the distribution is in the northern and southern sky, but the distribution is much higher in the southern sky (poleward) of Pontianak. The sky plot of occurrence percentage shows that the distribution is concentrated in the southern sky of Pontianak, as shown in Fig. 7d-f. However, Fig. 7f shows that ionospheric scintillation occurrences also occur in the northern sky (equatorward) of Pontianak. Another interesting feature found in Fig. 7e and

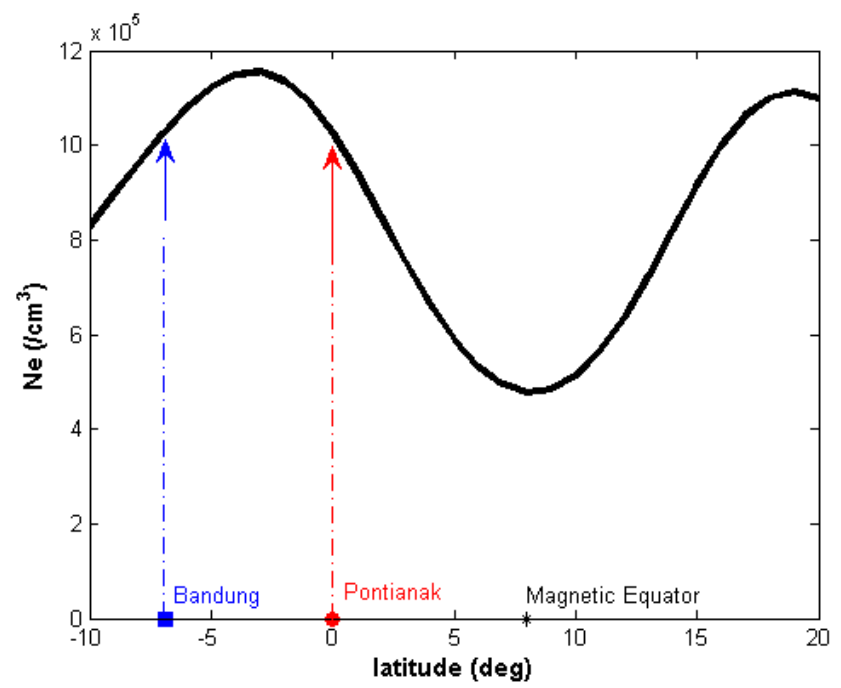

Fig. 8. The typical condition of electron density plotted against latitude in the Indonesian sector.

$\mathrm{f}$ is the higher distribution concentration in the southern sky, with more scintillation occurrences westward of Pontianak (220-260 degrees in azimuth).

Figure 8 shows a typical latitudinal distribution of maximum electron density $(\mathrm{NmF} 2)$ taken from the IRI-90 (International Reference Ionosphere 1990) model (Bilitza et al., 1993) in March 2011 at the Indonesian sector. The figure shows that the crest region is typically located between Bandung and Pontianak. Thus, concentrations of scintillation occurrences in the northern sky of Bandung and in the southern sky of Pontianak can be ascribed to the average locations of the EIA crest.

However, the location of the EIA crest cannot explain the second enhancement of scintillation occurrences in the northern sky of Pontianak, as shown in Fig. 7f. Furthermore, the maximum occurrences at $20-30^{\circ}$ elevation angles in the northern sky of Bandung, as shown in Fig. 6f, cannot be explained by the location of the EIA. Because the scintillation occurrence at 20-30 degrees is higher than those at lower elevation angles, these maximum occurrences cannot be explained by longer propagation paths in the ionosphere at lower elevation angles either. We assumed that these findings are due to the same effect, which is associated with magneticfield-aligned irregularities. Herman (1966) concluded that magnetic-field-aligned irregularities undoubtedly exist, with the strongest irregularities existing near the peak of the electron density in the F region (normally $300 \mathrm{~km}$ ). Previous studies have confirmed that scintillation is controlled by magnetic field direction at high and mid-latitudes. Maurits et al. (2008) investigated the enhancement effect of ionospheric scintillation on high-latitude propagation direction paths close to the geomagnetic field line. Afraimovich et al. (2011) reported the first evidence that total GPS L2 phase slips over Japan (mid-latitude) were caused by GPS signal 

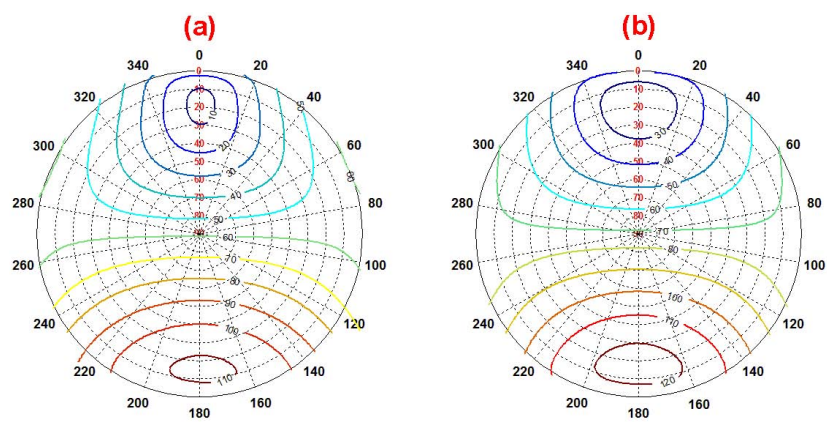

Fig. 9. Angles between the lines of sight (LOS) and magnetic field line at an altitude $300 \mathrm{~km}$ as observed from (a) Bandung and (b) Pontianak.

scattering at mid-latitude FAI (field-aligned irregularities) for the lines of sight (LOS) (both across and aligned to the magnetic field line). In a GPS radio occultation experiment, Anderson and Straus (2005) reported scintillation enhancement in the field-aligned directions (i.e. scintillation between GPS satellites and low-Earth-satellite orbit paths at the equatorial region). Thus, by ground-based observation in the lowlatitude region, our findings support that ionospheric scintillation frequently occurs around the direction of the magnetic field line.

Figure $9 \mathrm{a}$ and $\mathrm{b}$ show the angles between the magnetic field line and LOS at an altitude of $300 \mathrm{~km}$ at Bandung and Pontianak, respectively. We used the IGRF model to calculate the angle between LOS and the magnetic field line. Figure 9a shows LOS that are close to the direction parallel to the magnetic field line (lower than 20 degrees), with elevation angles between 10 and 30 degrees in the northern sky of Bandung. The peak in scintillation occurrence at Bandung falls in the near-field-parallel direction. Figure $9 \mathrm{~b}$ shows that the lowest angle between LOS and the magnetic field line is 30 degrees, with elevation angles between 10 and 40 degrees in the northern sky of Pontianak. Figure 10 shows the geometries between LOS and the magnetic field line, with elevation angles of 20 and 30 degrees, an azimuth angle of 0 degrees (north), and a magnetic field line at $300 \mathrm{~km}$ for both Bandung and Pontianak. Although the minimum angle between LOS and the magnetic field line is not as small as that for Bandung, the second peak in scintillation occurrence at Pontianak also falls within the near-field-parallel directions. This is a plausible explanation for why scintillations also occurred in the northern sky of Pontianak. From this analysis, the enhancement of scintillation in the field-parallel direction observed from ground measurement was determined for the first time. Our finding is the first to confirm the field-parallel effect on the ground at the low-latitude region by showing consistency between magnetic inclination and scintillation enhancement directions. The use of sigma-CCDiv filtering enables us to exclude contamination by multipath effects, making field-parallel effects detectable from the ground for

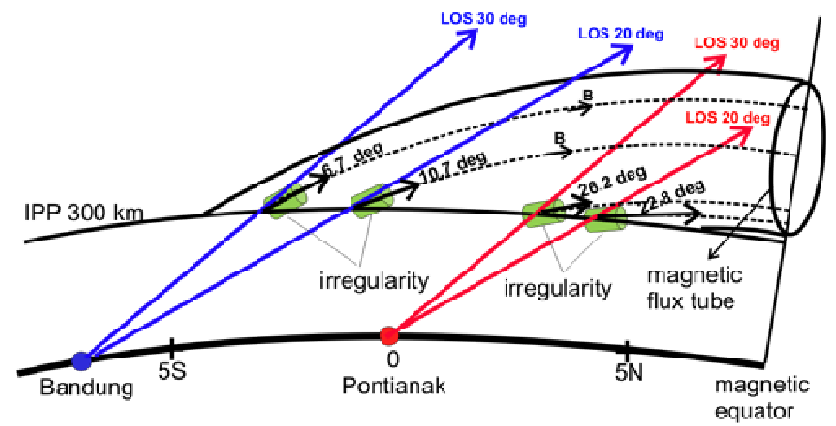

Fig. 10. Geometries between LOS and the magnetic field line at elevation angles of 20 and 30 degrees in the north with respect to Bandung and Pontianak.

the first time. Previously, such effects had been difficult to detect with the traditional $30^{\circ}$ elevation mask because the field-parallel directions in low-latitude regions have elevation angles lower than 30 degrees. This has an important implication for GNSS applications, such as aviation, where satellites with elevation angles down to 5 degrees are used.

Another interesting feature found in Fig. 7e and $\mathrm{f}$ is the higher scintillation occurrences in the southwest direction with respect to Pontianak. This feature can be ascribed to the three-dimensional structure of the plasma bubble. Generally, plasma bubbles are tilted westward as they vertically develop, which is due to vertical shear in the eastward plasma drift in the F region (Zalesak et al., 1982; Bernhardt, 2007). This indicates that the plasma bubble will be tilted westward with increasing latitude (Mendillo and Baumgardner, 1982). Consequently, the plasma bubble shows a "C" shape, as reported by Kelley et al. (2003) when it was mapped along the magnetic field line on the horizontal plane at a certain altitude. Additionally, scintillations may be stronger in the west, where the LOS tend to be parallel to the plasma bubble structure, and lower in the east with respect to the receiver site. Figure 11 shows an illustration for describing LOS from the receiver to the east of the bubble (which should be pointed westward to be parallel to the wall of the bubble) and LOS from the receiver to the west of the bubble (which should be pointed eastward to go across the bubble). There is a largescale tendency in the electron density to be higher in the west and lower in the east, and this might contribute to the higher occurrence in the westward direction. It is important to note that the results shown here were obtained by a statistical analysis over the entire night (local time); however, as representative of all occurrences, the east-west density gradient should not be affected, because the east and west LOS should pass the same volume. Thus, our finding is consistent with the latitudinal structure of plasma bubbles that are tilted westward as they develop vertically and poleward. 


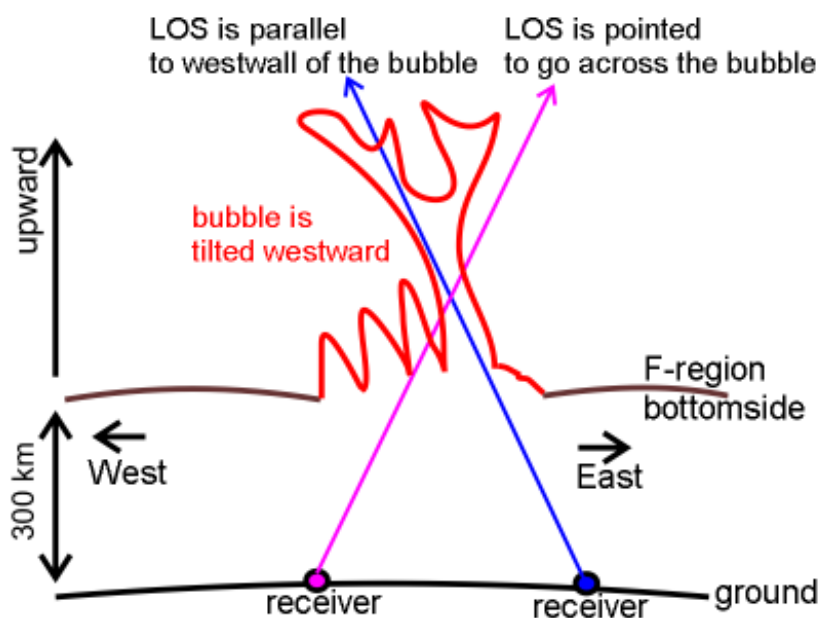

Fig. 11. An explanation of the geometry between LOS from the receiver to the east and west of the plasma bubble.

\subsection{Post-midnight scintillations}

One interesting result obtained from this study is the postmidnight scintillation occurrence, which often occurs after midnight without post-sunset scintillation at earlier local times. In general, we found that most of those scintillations are weaker in intensity, less frequent, and over a shorter interval than post-sunset scintillations. Furthermore, they are more frequently observed in May, July, June, and December (the non-plasma-bubble season). The occurrence characteristics are different from those of the plasma bubbles. As shown in Fig. 12, the scintillations in 2011 at Bandung are very clear. However, the scintillations at Pontianak were much less than Bandung, which is the most intriguing difference between the Bandung and Pontianak analyses. In 2011, we determined that the day numbers with post-midnight scintillation occurrence at Bandung are 128, 132, 138, 140, 142, $144,154,155,159,160,170,185,207,211,326$, and 340 ; the magnetic activities were low to moderate during these days, with $\sum \mathrm{Kp}$ levels of $3+, 4-, 11-, 3+, 8+, 12-, 6+$, $12+, 18-, 16+, 7-, 17+, 11+, 17+, 14-$, and 5+, respectively.

Otsuka et al. (2009) reported post-midnight FAI that were detected by VHF radar at $30.8 \mathrm{MHz}$ at Kototabang $\left(0.20^{\circ} \mathrm{S}\right.$, $100.32^{\circ} \mathrm{E}$; dip latitude $10.4^{\circ} \mathrm{S}$ ); this magnetic latitude is very similar to Pontianak, and the FAI were not accompanied by GPS scintillation. A lower occurrence of post-midnight scintillation at Pontianak is consistent with the results obtained by Otsuka et al. (2009), though they used a $30^{\circ}$ elevation mask to analyse the scintillation data. These authors concluded that the irregularities associated with the VHF radar echo were too weak to cause scintillation of GPS signals. However, our finding of the post-midnight scintillation at Bandung in 2011 shows that there can be some irregularities
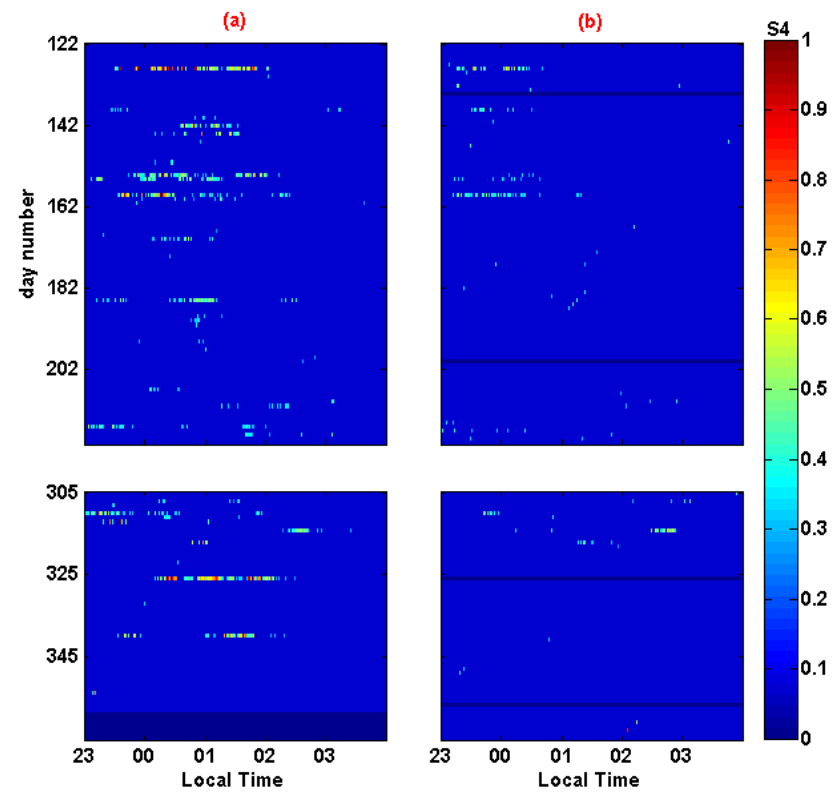

Fig. 12. Post-midnight scintillation occurrences for (a) Bandung and (b) Pontianak in 2011 in the non-plasma-bubble season.

that can cause scintillations of GPS signals at different locations in the post-midnight period.

Why were the post-midnight scintillations not observed in previous works? Figure 13a shows that the post-midnight scintillations are concentrated at low elevation angles in the northern sky of Bandung. In previous studies, it was common to conduct GPS scintillation data analyses using a $30^{\circ}$ elevation mask to avoid multipath effects and achieve a low signal-to-noise level. With the simple elevation angle masking, these scintillations may have been missed. Figure 13b and $\mathrm{c}$ show a comparison between the scintillation occurrences at Bandung in 2011 with the sigma-CCDiv filter adjusted down to $10^{\circ}$ elevation angles (Fig. 13b) and those with only the traditional $30^{\circ}$ elevation mask (Fig. 13c). Most of the post-midnight scintillations are eliminated, and only a few strong ones remained following the use of the $30^{\circ}$ elevation mask, as shown in Fig. 13c. However, the diagonal patterns that are indicative of multipath effects remain visible, indicating that the multipath effect is still found with the $30^{\circ}$ elevation mask. This may be ascribed to the antenna environment on the roof of the buildings. However, we still find more post-midnight scintillations using the sigma-CCDiv filter, as shown in Fig. 13b. By comparing these filter techniques, the post-midnight scintillations observed at Bandung occur mostly at elevation angles lower than 30 degrees and may have been missed in the previous studies with a traditional elevation mask of 30 degrees.

The next question is why the post-midnight occurrences were observed at Bandung but not at Pontianak. The LOS at low elevation angles in the northern sky of Bandung pass over a longer period in the equatorial anomaly crest region, 

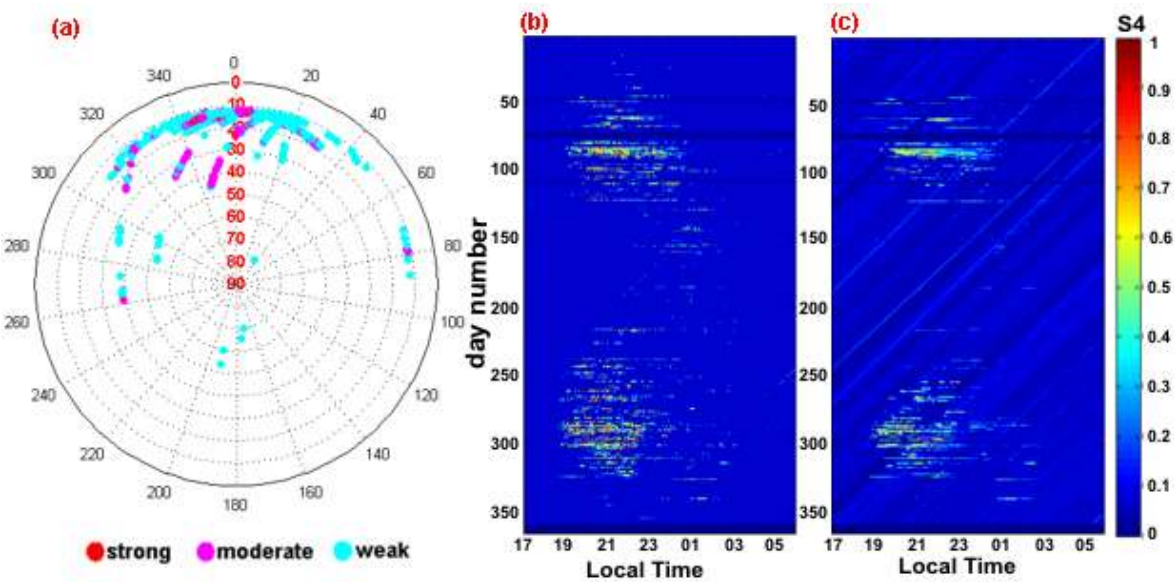

Fig. 13. (a) A directional plot for post-midnight scintillations in the non-plasma-bubble season observed at Bandung in 2011 and comparison between the scintillation occurrences at Bandung in 2001 with (b) the sigma-CCDiv filter with data at elevation angles down to $10^{\circ}$ and (c) the traditional $30^{\circ}$ elevation mask only.

where the background density is high. In addition, the LOS that are less than 30 degrees from Bandung pointing equatorward are nearly parallel with the magnetic field line at $300 \mathrm{~km}$ in altitude. Thus, a possible explanation of the postmidnight scintillation occurrence at Bandung is that the amplitude of irregularities in certain directions may be effectively enhanced due to the background density enhancement by the EIA, larger slant factor, and field-parallel effects. At Pontianak, the amplitude of irregularities enhanced by the EIA is satisfied; however, the slant factor is smaller due to the high elevation angle and field-parallel effects are not satisfied because of the LOS from Pontianak pointing southward. Because post-midnight scintillations are weak, they would not be observed at Pontianak if any of the required conditions (high background density, field-parallel factor, and larger slant factor) were missing. To test this hypothesis, post-midnight scintillation analyses with a lower elevation angle cut-off at a different magnetic latitude are necessary.

Previous studies on post-midnight irregularities in nonplasma-bubble seasons suggested that they could be associated with the plasma bubble or due to MSTID (mediumscale travelling disturbance) propagating from mid-latitude to low latitude. It is unclear why the plasma bubble can occur in the post-midnight period and in a non-plasma-bubble season. In addition, it is also unclear whether a mid-latitude MSTID can propagate down to the low-latitude region. However, our analysis cannot provide a definitive answer as to the mechanism that could cause the post-midnight scintillations. Nevertheless, our finding of post-midnight scintillations and the conditions for scintillations' enhancement are important, as they provide additional information to assist in the understanding of the potential mechanism.

\section{Conclusions}

We studied low-latitude ionospheric scintillations in the Indonesian sector during the period 2009-2011 using a GPS scintillation receiver (GSV4004B) installed at Bandung and Pontianak. We analysed the climatological and directional characteristics. Directional analyses can be used to study the relationship between the satellite-receiver link and spatial structure of ionospheric irregularities. The following are the results obtained from the present study.

1. The seasonal-local time variation of post-sunset scintillations in the Indonesian sector can be ascribed to the plasma bubble. We found two peak occurrences of post-sunset scintillations during the equinox months, which are called plasma bubble seasons for the Indonesian sector, and they were enhanced as solar activity increased from 2009 to 2011.

2. The distribution of scintillations is concentrated in the EIA crest region, which has an average location between Bandung and Pontianak. The result obtained from directional analyses of Bandung and Pontianak data indicates that a higher distribution of scintillations is concentrated in the northern sky of Bandung and in the southern sky of Pontianak.

3. Our most remarkable finding is that enhanced the scintillation occurrences in the field-aligned directions are likely to be affected by field-aligned plasma irregularities. This is reported for the first time by groundbased observation in a low-latitude region. We found a second enhancement of scintillation occurrences in the northern sky of Pontianak that cannot be explained by the location of EIA crest. Additionally, we found most of the scintillation occurrences at elevation angles of 20-30 degrees in the northern sky of Bandung, rather 
than at lower elevation angles, due to the longer signal path propagation in the ionosphere.

4. For Pontianak, we found a higher distribution of scintillations in the southwest direction, which is likely associated with the plasma bubble structure being tilted westward with increasing latitude.

5. Post-midnight scintillations in the non-plasma-bubble seasons that had not been reported in previous studies were observed at Bandung in 2011 (few were observed at Pontianak). The post-midnight scintillations were concentrated at low elevation angles equatorward of Bandung. These scintillations may have been missed in previous studies due to elevation angle masking at 30 degrees. The higher occurrence of post-midnight scintillation at Bandung versus Pontianak is because the satellite-receiver paths at low elevation angles in the northern sky of Bandung pass longer in the EIA crest region and are in the field-aligned direction. To test this hypothesis, a post-midnight scintillation analysis with a lower elevation angle cut-off at different magnetic latitudes is necessary.

Acknowledgements. P. Abadi would like to thank the Indonesian Ministry of Research and Technology (KEMENRISTEK) for supporting his apprenticeship at ENRI during the three months of this study. In addition, he would also like to thank LAPAN for partial financial assistance in conducting this study and operating the GPS receivers in Bandung and Pontianak since 2008.

Topical Editor K. Hosokawa thanks E. de Paula and one anonymous referee for their help in evaluating this paper.

\section{References}

Afraimovich, E. L., Ishin, A. B., Tinin, M. V., Yasyukevich, Yu, V., and Jin, S. G.: First evidence of anisotropy of GPS phase slips caused by the mid-latitude field-aligned ionospheric irregularities, Adv. Space Res., 47, 1674-1680, 2011.

Anderson, P. C. and Straus, P. R.: Magnetic field orientation control of GPS occultation observations of equatorial scintillation, Geophys. Res. Lett., 32, L21107, doi:10.1029/2005GL023781, 2005.

Basu, S., Basu, S., Aarons, J., MacClure, J. P., and Cousins, M. D.: On the coexistence of kilometer- and meter-scale irregularities in the nighttime equatorial F region, J. Geophys. Res., 83, 42194226, doi:10.1029/JA083iA09p04219, 1978.

Basu, S., MacKenzie, E., and Basu, S.: Ionospheric constraints on VHF/UHF communications links during solar maximum and minimum periods, Radio Sci., 23, 363-378, 1988.

Basu, S., Groves, K. M., Basu, S., and Sultan, P. J.: Specification and forecasting of scintillations in communication/navigation links: current status and future plans, J. Atmos. Sol.-Terr. Phys., 64, 1745-1754, 2002.

Beniguel, Y., Romano, V., Alfonsi, L., Aquino, M., Bourdillon, A., Cannon, P., De Franceschi, G., Dubey, S., Forte, B., Gherm, V.,
Jakowski, N., Materassi, M., Noack, T., Pozoga, M., Rogers, N., Spalla, P., Strangeways, H. J., Warrington, E. M., Wernik, A., Wilken, V., and Zernov, N.: Ionospheric scintillation monitoring and modelling, Ann. Geophys.-Italy, 52, 391-416, 2009.

Bernhardt, P. A.: Quasi-analytic models for density bubbles and plasma clouds in the equatorial ionosphere: 2. A simple langrangian transport model, J. Geophys. Res., 112, A11310, doi:10.1029/2007JA012287, 2007.

Bilitza, D., Rawer, K., Bossy, L., and Gulyaeva, T.: International reference ionosphere - past, present, future: I. Electron density, Adv. Space Res., 13, 3-13, 1993.

Burke, W. J., Huang, C. Y., Gentile, L. C., and Bauer, L.: Seasonallongitudinal variability of equatorial plasma bubbles, Ann. Geophys., 22, 3089-3098, doi:10.5194/angeo-22-3089-2004, 2004.

de Paula, E. R., Rodrigues, F. S, Iyer, K. N., Kantor, I. J., Abdu, M. A, Kintner, P. M., Ledvina, B. M., and Kil, H.: Equatorial anomaly effects on GPS scintillations in Brazil, Adv. Space Res. 31, 749-754, 2003.

de Paula, E. R., Muella, M. T. A. H., Sobral, J. H. A., Abdu, M. A., Batista, I. S., Beach, T. L., and Groves, K. M.: Magnetic conjugate point observations of kilometre and hundred-meter scale irregularities and zonal drifts, J. Geophysc. Res., 115, A08307, doi:10.1029/2010JA015383, 2010.

Doumouya, V. and Cohen, Y.: Improving and testing the empirical equatorial electrojet model with CHAMP satellite data, Ann. Geophys., 22, 3323-3333, doi:10.5194/angeo-22-33232004, 2004.

Dubey, S., Wahi, R., and Gwal, A. K.: Ionospheric effects on GPS positioning, Adv. Space Res., 38, 2478-2484, 2006.

Herman, J. R.: Spread F and ionospheric F-region irregularities, Rev. Geophys., 4, 255-299, doi:10.1029/RG004i002p00255, 1966.

Kelley, M. C., Makela, J. J., Paxton, L. J., Kamalabadi, F., Comberiate, J. M., and Kil, H.: The first coordinated ground- and spacebased optical observations of equatorial plasma bubbles, Geophys. Res. Lett., 30, 1766, doi:10.1029/2003GL017301, 2003.

Maruyama, T. and Matuura, N.: Longitudinal variability of annual changes in activity of equatorial spread $\mathrm{F}$ and plasma bubbles, J. Geophys. Res., 89, 10903-10912, 1984.

Maurits, S. A., Gherm, V. E., Zernov, N. N., and Strangeways, H. J.: Modelling of scintillation effects on high-latitude transionospheric paths using ionospheric model (UAF EPPIM) for background electron density specifications, Radio Sci., 43, RS4001, doi:10.1029/2006RS003539, 2008.

Mendillo, M. and Baumgardner, J.: Airglow characteristics of equatorial plasma depletions, J. Geophys. Res., 87, 7641-7652, 1982.

Ogawa, T., Sagawa, E., Otsuka, Y., Shiokawa, K., Immel, T. I., Mende, S. B., and Wilkinson, P.: Simultaneous ground- and satellite-based airglow observations of geomagnetic conjugate plasma bubbles in the equatorial anomaly, Earth Planet. Space, 57, 385-392, 2005.

Otsuka, Y., Shiokawa, K., and Ogawa, T.: Equatorial ionospheric scintillations and zonal irregularity drifts observed with closelyspaced GPS receivers in Indonesia, J. Meteorol. Soc. Jpn., 84A, 343-351, 2006.

Otsuka, Y., Ogawa, T., and Effendy: VHF radar observations of nighttime F-region field- aligned irregularities over Kototabang, Indonesia, Earth Planet. Space, 61, 431-437, 2009. 
Pi, X., Mannucci, A. J., Lindqwister, U. J., and Ho, C. M.: Monitoring of global ionospheric irregularities using the worldwide GPS network, Geophys. Res. Lett., 24, 2283-2286, 1997.

Seo, J., Walter, T., and Enge, P.: Correlation of GPS signals fades due to ionospheric scintillation for aviation applications, Adv. Space. Res., 47, 1777-1788, 2011.

Tsunoda, R. T.: Control of the seasonal and longitudinal occurrence of equatorial scintillations by the longitudinal gradient in integrated E region Pederson conductivity, J. Geophys. Res., 90, 447-456, 1985.
Van Dierendonck, A. J. and Hua, Q.: Measuring ionospheric scintillation effects from GPS signals, ION 57th Annual Meeting/CIGTF 20th Biennial Guidance Test Symposium, Albuquerque, NM, 11-13 June 2001, 2001.

Zalesak, S. T., Ossakow, S. L., and Chaturvedi, P. K.: Nonlinear equatorial spread F: The effect of neutral winds and background Pederson conductivity, J. Geophys. Res., 87, 151-166, 1982. 